\title{
CAPITULO 84
}

\section{RELATO DE EXPERIÊNCIA DO PROJETO DE EXTENSÃO ANATO ACADEMY: JOVENS DO ENSINO MÉDIO APRENDENDO SOBRE O CORPO HUMANO}

DOI 10.4322/978-65-995353-2-1.c84

$\underline{\text { Ana Priscila Franca Correia }}{ }^{1}$, Carlos Kaylan Souza Batista ${ }^{2}$, Diego Bitu de Meloº ${ }^{2}$ Francisca Ana Lívia Rodolfo da Silva², Gleyciane Lins Pereira $^{2}$, Karen Maria Ferreira Tavares ${ }^{2}$, Larissa Thaís de Melo Filizola ${ }^{2}$, Letícia Bezerra Barroso $^{2}$, Ranielly Lara Corpe Teixeira ${ }^{2}$, Jalles Dantas de Lucena ${ }^{3}$.

\footnotetext{
${ }^{1}$ Acadêmico em Medicina pela Faculdade Santa Maria - FSM (francaanapriscila@gmail.com), ${ }^{2}$ Acadêmico em Medicina pela Faculdade Santa Maria - FSM , ${ }^{3}$ Docente da Faculdade Santa Maria - FSM (jallesdantas@gmail.com).
}

\section{RESUMO}

O anato academy é um projeto de extensão que foi idealizado pelo professor da disciplina de Correlações Anatomoclínicas, juntamente com alguns alunos do curso de Medicina da FSM. Com a finalidade de difusão do conhecimento anatômico para os jovens do ensino médio, principalmente, para aqueles que a posteriori realizarão o ENEM. O objetivo desse trabalho é relatar a dinâmica do projeto, bem como, suas modificações ocasionadas pela deflagração da pandemia do Sars-CoV-2 e experiências vivenciadas pelos extensionistas. O método utilizado trata-se de um relato de experiência sobre o ensino anatômico para o ENEM e de educação em saúde, vivenciada pelos participantes do projeto de extensão "Anato Academy", vinculado ao curso de Medicina da FSM, Cajazeiras (PB), durante os anos de 2020 e 2021, tendo como público-alvo estudantes do primeiro ao terceiro ano do ensino médio de escolas públicas e particulares. Para isso, os alunos extensionistas do Anato Academy produziram cartilhas educativas, sobre doenças comuns nos sistemas orgânicos, e uma coleção de apostilas com conhecimento anatômico direcionado para o ENEM. Nesse sentido, o projeto obteve o êxito esperado ao conseguir ampliar o acesso à informação dos estudantes beneficiados com os materiais produzidos, ao mesmo tempo que expandia as vivencias dos extensionistas. Dessa 
forma, o projeto foi incisivo nas estratégias de melhorias do ensino anatômico e de educação em saúde.

Palavras-chave: Anatomia, Educação em Saúde e COVID-19.

Área Temática: Ciências da Saúde.

E-mail do autor principal: francaanapriscila@gmail.com

\section{INTRODUÇÃOO}

A Constituição Brasileira de 1988 tem como cláusula pétrea no Art. 205 "a educação como um direito de todos e dever do Estado" (BRASIL, 1988). Tendo este, a responsabilidade de incentivar e buscar melhorias no que concerne ao pressuposto.

Contudo, a pandemia do SARS-CoV-2 evidenciou grandes problemas relacionados ao processo educativo brasileiro. Segundo o IBGE (Instituto Brasileiro de Geografia e Estatística) 4,3 milhões de estudantes no país entraram na pandemia sem acesso à internet, pelos mais variados fatores, como: inacessibilidade a computadores ou celulares, baixas condições financeiras para o custeio dos gastos de rede e indisponibilidade de serviço na região em que vivem (PAMPLONA, 2021).

Adjunto a estes fatores de exclusão digital, observou-se ainda, uma dificuldade no estabelecimento e organização da rotina dos estudos, problemas de relacionamentos interpessoais nas aulas, e o não funcionamento de muitas escolas de forma remota, principalmente as de âmbito público. Resultando assim, em uma defasagem no sistema de ensino do país (PROGEPE, 2020).

Quadro este que evidenciou ainda mais a importância de um projeto de extensão como meio de propagação do conhecimento e de tentativa de acesso mais igualitário ao ensino (ABRANCHES, 2020). Então, baseando-se no pressuposto, o Projeto de extensão Anato Academy foi idealizado pelo professor da disciplina de Correlações Anatomoclínicas, juntamente com alguns alunos do curso de Medicina da Faculdade Santa Maria (FSM), com o objetivo de disseminação de conteúdo anatômico para estudantes do ensino médio de escolas públicas e particulares da cidade de Cajazeiras, que vão realizar o Exame Nacional do Ensino Médio (ENEM).

A priori, o projeto foi pensado para acontecer de forma presencial, com a observação e o estudo em laboratório da Anatomia Humana através de peças cadavéricas. Contudo, com a deflagração da pandemia, e a suspensão das aulas presenciais, o projeto se reinventou, sendo realizadas muitas atividades de cunho informativo, como a criação de redes informativas onde

\section{E - book Tripé do Ensino Superior: Ensino,} Pesquisa e Extensão 
aconteceram posts semanais, produção de cartilhas educativas para a distribuição em escolas públicas e particulares, e produção de apostilas com material didático de Anatomia Humana voltado para o ENEM (UFCA, 2020).

Evidenciando então, a importância deste, tanto para os extensionistas pela experiência na divulgação do conhecimento, bem como para muitos estudantes do ensino médio da cidade de Cajazeiras, que estavam sem participar de aulas remotas e com déficit nos conteúdos de ciências (UFES, 2021).

\section{OBJETIVO}

O objetivo deste artigo é relatar a experiência vivenciada por um grupo de 9 discentes do curso de Medicina da Faculdade Santa Maria (FSM), participantes do projeto de extensão "Anato Academy", durante as atividades de educação em saúde e de ensino anatômico para o Exame Nacional do Ensino Médio (ENEM), para alunos do ensino médio de escolas públicas e particulares da cidade de Cajazeiras, Paraíba.

\section{METODOLOGIA}

Almeida (2007) destaca que "um relato de experiência propõe tornar visível e compartilhar com outros profissionais e estudantes uma vivência prática”. Nesse contexto, este relato de experiência descreve às experiências do ensino anatômico para o ENEM e de educação em saúde, vivenciada pelos participantes do projeto de extensão "Anato Academy”, vinculado ao curso de Medicina da Faculdade Santa Maria (FSM), Cajazeiras, Paraíba.

O conhecimento da realidade possibilita definir o que é necessário conhecer naquele momento, o que pode ser trabalhado pelo aluno durante o período e o que necessita ser aprofundado no período subsequente (ALVES, 2020).

Assim, as atividades de extensão foram desenvolvidas com os estudantes do ensino médio, do primeiro ao terceiro ano, de escolas públicas e particulares da cidade de Cajazeiras (PB), durante os semestres de 2020.2 e 2021.1. As atividades foram executadas por um grupo de 9 discentes do curso de Medicina da Faculdade Santa Maria (FSM) e pelo professor da disciplina de Correlações Anatomoclínicas, como coordenador do Projeto. Os membros do Anato Academy participavam semanalmente de reuniões pela plataforma virtual de 
videochamadas Google Meet®, em que ocorriam atividades de capacitação e planejamento das atividades desenvolvidas pelo Projeto.

Inicialmente, os membros do Projeto foram divididos em 3 grupos, com 3 extensionistas cada, que ficaram responsáveis por determinados sistemas orgânicos abordados no Anato Academy (Tabela 1).

O projeto de extensão Anato Academy teve como principal objetivo no seu primeiro ano de atuação, nesse contexto de isolamento social e de aulas remotas devido a pandemia da Covid-19, a criação de uma conta na rede social Instagram ${ }^{\circledR}$, para divulgação do projeto e fácil acesso às informações pelo público interessado. Esta rede social foi escolhida pelo fato da sua plataforma apresentar uma variedade de ferramentas, permitindo a publicação de conteúdos de formas variadas. Foi instituído, portanto, que as informações seriam publicadas em formato de posts, facilitando o fácil acesso aos conteúdos. Os assuntos mais robustos foram divulgados em forma de texto e publicados no feed, enquanto que outros conteúdos menores, foram publicados em formato de tópicos através dos stories.

Dessa forma, utilizando de variadas formas de apresentação de conteúdo do Instagram ${ }^{\circledR}$, conseguiu-se proporcionar de forma prática, interativa e bem aceita no cenário atual, a transmissão de informações e conteúdos propostos pelo projeto. Além disso, as ferramentas utilizadas como os stories - os quais, de maneira rápida e precisa, levaram conteúdo rapidamente absorvível -, e o feed - o qual foi uma fonte de interação com os internautas, por meio dos comentários; permitiram um feedback sobre as informações divulgadas na rede social do Anato Academy, possibilitando uma análise do conteúdo produzido, permitindo que melhorias acontecessem durante seu primeiro ano de atuação.

Concomitante a isso, houve a produção de cartilhas educativas, com temas voltados para educação em saúde de algumas doenças comuns nos sistemas orgânicos (Tabela 2), e de uma coleção de apostilas com material didático sobre Anatomia Humana, voltada, principalmente, para o ENEM, com o intuito de serem compartilhadas com os alunos de escolas públicas e particulares do ensino médio da cidade de Cajazeiras, beneficiadas pelo projeto. Em especial, aquelas na qual os alunos tiveram menor interação na rede social devido a dificuldades de acesso à internet e aparelhos digitais.

Assim, devido ao uso desses recursos, os alunos participantes tiveram acesso a recursos didáticos com conteúdo sobre Anatomia e questões de vestibulares sobre importantes temas, ampliando as possibilidades de acesso à informação, como também, a expansão e exercício de seus conhecimentos.

\section{E - book Tripé do Ensino Superior: Ensino, Pesquisa e Extensão}


Tabela 1. Formação dos grupos com seus membros e sistemas orgânicos abordados no Anato Academy.

\begin{tabular}{ccc}
\hline Grupos & Membros & Sistemas \\
\hline 1 & A. P. F. C. & Respiratório \\
\cline { 2 - 3 } & G. L. P. & Locomotor \\
& R. L. C. T. & Digestório \\
\hline & F. A. L. R. S. & Circulatório \\
\hline & L. B. B. & Reprodutor \\
\hline & D. B. M. S. & Urinário \\
\hline & L. T. M. F. & Endócrino
\end{tabular}

Fonte: Autores, 2021.

Tabela 2. Temas abordados nas cartilhas educativas.

\begin{tabular}{|c|c|c|}
\hline Grupos & Sistemas & Temas abordados \\
\hline \multirow{2}{*}{1} & Respiratório & $\begin{array}{l}\text { COVID-19, Asma, DPOC, } \\
\text { Pneumonia, Tuberculose }\end{array}$ \\
\hline & Locomotor & $\begin{array}{c}\text { Osteoporose, Fibromialgia, } \\
\text { Artrite Reumatóide }\end{array}$ \\
\hline \multirow{2}{*}{2} & Digestório & $\begin{array}{c}\text { Apendicite, Gastrite, } \\
\text { Colelitíase, Úlcera peptica }\end{array}$ \\
\hline & Circulatório & $\begin{array}{c}\text { Insuficiência Venosa, TVP, } \\
\text { Ateriosclerose, IAM }\end{array}$ \\
\hline \multirow{3}{*}{3} & Reprodutor & $\begin{array}{c}\text { Dismenorreia, HPV, câncer } \\
\text { de mama, HPB, } \\
\text { Adenocarcinoma de próstata }\end{array}$ \\
\hline & Endócrino & $\begin{array}{l}\text { Diabetes Mellitus, } \\
\text { Hipotireoidismo, } \\
\text { Hipertireoidismo }\end{array}$ \\
\hline & Urinário & $\begin{array}{c}\text { ITU, Litíase } \\
\text { Glomerulonefrite }\end{array}$ \\
\hline
\end{tabular}

Fonte: Autores, 2021. 


\section{RESULTADOS E DISCUSSÕES}

Neste tópico apresentamos alguns resultados alcançados a partir da proposta do projeto de extensão "Anatomia para alunos do ensino médio" em desenvolvimento.

Até o momento, os alunos extensionistas executaram parte das atividades planejadas para o projeto de extensão. Eles, desde o início do projeto, participaram semanalmente de reuniões pelo Google Meet ${ }^{\circledR}$ para planejamento das atividades desenvolvidas pelo Projeto.

Desde o início da execução do Projeto os extensionistas produziram o material didático distribuído aos estudantes das escolas parceiras desse projeto. Foram selecionados, em discussão entre os extensionistas e o coordenador do Anato Academy, alguns assuntos já apresentados na tabela 2. Estes temas foram selecionados baseados nos conteúdos de Anatomia Humana presentes nas últimas provas do ENEM.

Após a produção dos primeiros materiais, foi iniciada a etapa de divulgação do Projeto nas redes sociais, para isso os alunos criaram uma conta no Instagram ${ }^{\circledR}$, que posssibilitou maior divulgação dos materiais produzidos. Na página eram divulgados semanalmente conteúdos de Anatomia voltados ao ensino médio e algumas doenças comuns nos sistemas orgânicos.

A partir disso, iniciamos os contatos com os diretores escolares e professores de Ciências do ensino médio das escolas públicas e privadas da cidade de Cajazeiras, afim de apresentar o referido Projeto, o material didático produzido e fecharmos parcerias com as escolas.

Além da produção de material para divulgação nas redes sociais, produzimos cartilhas educativas com temas voltados para educação em saúde de algumas doenças mais comuns nos sistemas orgânicos, que foram distribuídas não apenas aos estudantes do ensino médio, mas também aos demais estudantes nas escolas. Os alunos do ensino médio vão fazer provas do ENEM, pensando nisso, também produzimos apostilas com material didático de Ciências, focado em Anatomia Humana, que foram compartilhadas inicialmente com os professores da disciplina para análise, e a seguir com os alunos. Por meio destas ferramentas, os alunos tiveram acesso a recursos didáticos com conteúdo sobre Anatomia e questões de vestibulares trabalhando os temas, além da possibilidade de poderem expandir e exercitar seus conhecimentos.

Percebemos muitas transformações nos alunos extensionistas mesmo antes de iniciarem efetivamente os encontros presenciais. Todas as etapas já mencionadas resultaram e vêm resultando positivamente na mudança de atitude e de percepção em relação à pesquisa, extensão e ensino. Os alunos extensionistas relatam constante aprendizado sobre a Anatomia Humana e 
estratégias de educação em saúde, tão importante para a formação médica. Neste sentido, podemos perceber que alguns dos resultados esperados já estão sendo alcançados, entre eles:

- Divulgação do projeto de extensão nas redes sociais Instagram®;

- Fechamento de parceiras com as escolas;

- Produção e início da distribuição de material educativo e para o ENEM, nas escolas;

- Os alunos extensionistas vêm gradativamente ampliando e aprimorando suas habilidades de comunicação;

- Os extensionistas relatam maior aprendizagem de Anatomia, por terem que estudar e produzir os materiais;

- Os extensionistas estão aprendendo a produzir conhecimento científico ao perceberem as práticas da pesquisa e da extensão. São incentivados a terem autonomia e iniciativa para a realização das atividades, o que se mostra um processo em desenvolvimento;

- Por fim, ainda que precoce, acreditamos que os estudantes das escolas públicas e privadas assistidos pelo Anato Academy, tiveram acesso a conhecimento anatômico que alguns não teriam em suas escolas, e que agora pode contribuir para um melhor desempenho no ENEM.

\section{CONSIDERAÇÕES FINAIS}

Os extensionistas do projeto vivenciaram estratégias de educação em saúde diante do cenário de pandemia, desenvolvendo maturidade ao utilizarem diversas ferramentas para alcançar o público do referido projeto. A maior parte do público-alvo beneficiado pelo projeto aconteceu através de conteúdo publicado nas redes sociais e do recebimento de material didático digital, outra parte com maiores dificuldades de acesso à internet pode participar ao receber material didático na forma de cartilhas e apostilas focadas nos sistemas orgânicos, conteúdo do ENEM. Durante o desenvolvimento dos primeiros passos do Anato Academy, aprendemos muito sobre a capacidade de reinventar, de adaptar e de ter empatia para conseguir que o projeto realmente fosse efetivo em contribuir com o acesso à informação.

Os extencionistas modificaram suas posturas diante do atual período, relembraram de momentos nos quais ainda estudavam para prestar o vestibular, diante disso, discutiram e aplicaram estratégias que acreditaram serem efetivas para ajudar de fato esses estudantes no

\section{E - book Tripé do Ensino Superior: Ensino,} Pesquisa e Extensão 
competitivo ENEM.

Nesse sentido, a principal limitação desse estudo foi a falta de coleta de dados acerca da efetividade da transferência de conhecimentos aos participantes do projeto, pois não foram realizados testes de aprendizagem devido à dificuldade de acesso e de horário em comum entre todos os estudantes participantes. Todavia, acreditamos que o referido projeto conseguiu oferecer conhecimento anatômico, minimizando os efeitos da pandemia no ensino de Ciências dos estudantes.

\section{REFERÊNCIAS}

ABRANCHES, Monica. Extensão Universitária remota? Os desafios em tempos depandemia. Jornal Pensar a Educação, 10 de julho de 2020. Disponível em:

$<$ https://pensaraeducacao.com.br/pensaraeducacaoempauta/extensao-universitaria-remota-osdesafios-em-tempos-de-pandemia/> . Acesso em: 17 de maio de 2021

ALMEIDA, L. H. R. B. et al. Ensinando e aprendendo com portadores de Esclerose Múltipla: relato de experiência. Revista Brasileira de Enfermagem, Brasília, v. 60, n. 4, p. 460-463, Aug. 2007.

ALVES, M. S. Relato de experiência no PRONATEC/MEDIOTEC. Revista Psicologia \& Saberes, v. 9, n. 15, p. 98-105, 2020.

BRASIL. Constituição (1988). Constituição da República Federativa do Brasil. Brasília, DF:Senado Federal: Centro Gráfico, 1988.

PAMPLONA, Nicola. Segundo IBGE, 4,3 milhões de estudantes brasileiros entraram na pandemia sem acesso à internet. Folha de São Paulo, Rio de Janeiro, 14 de abril de 2021. Disponível em: <https:/www1.folha.uol.com.br/educacao/2021/04/segundo-ibge-43-milhoesde-estudantes-brasileiros-entraram-na-pandemia-sem-acesso-a-internet.shtml>. Acesso em: 13 de maio de 2021. 
PROGEPE. Relacionamentos interpessoais em tempos de confinamento: dicas para lidar com conflitos. Disponível em: http://www.uff.br/?q=relacionamentos-interpessoais-emtempos-de-confinamento-dicas-para-lidar-com-conflitos. Acesso em: 15 de maio de 2021.

UFCA. A Extensão em tempo de pandemia: atuação das ações durante o isolamento social. Universidade Federal do Cariri. 2020. Disponível em:

$<$ https://www.ufca.edu.br/noticias/a-extensao-em-tempo-de-pandemia-atuacao-das-acoesdurante-o-isolamento-social/>. Acesso em: 17 de maio de 2021.

UFES. Ações de Extensão da Ufes no enfrentamento à pandemia de Covid-19. Próreitoria de extensão da UFES. 2021. Disponível em: <https://proex.ufes.br/conteudo/acoes-deextensao-da-ufes-no-enfrentamento-pandemia-de-covid-19>. Acesso em: 17 de maio de 2021. 